\title{
Os espaços do Eu e do Outro: a tematização da desigualdade social no documentário brasileiro Um lugar ao sol
}

\author{
Natália Martins Flores \& Isaltina Maria de Azevedo Mello Gomes*
}

Resumo: Investiga-se a construção discursiva de Um lugar ao sol (2009), de Gabriel Mascaro procurando compreender como seu discurso tematiza a desigualdade social brasileira. Mobilizam-se os conceitos da análise do discurso (Maingueneau, 2008a; 2008b) e os estudos de Penafria (1999) e Nichols (2001). A distinção das posições espaciais/sociais do Eu - morador de cobertura - e do Outro e a construção de sujeitos atrelados a valores de superioridade, privilégio e individualismo permite ao documentarista denunciar a alienação social.

Palavras-chave: cidades; urbanização; análise do discurso; desigualdade social; documentário.

Resumen: Se investiga la construcción discursiva de Um lugar ao sol (2009), de Gabriel Mascaro tratando de entender el modo en que su discurso tematiza la desigualdad social brasileña. Se movilizan para ello los conceptos del análisis del discurso (Maingueneau, 2008) junto a los estudios de Penafria (1999) y Nichols (2001). La distinción de las posiciones espaciales/sociales del yo (habitante de "cobertura" o ático) y del otro, y la construcción de sujetos sometidos a valores de superioridad, privilegio e individualismo permiten al documentalista denunciar la alienación social.

Palabras clave: ciudades; urbanización; análisis del discurso; desigualdad social, documental.

Abstract: We investigate the discursive construction of Um lugar ao Sol (2009), by Gabriel Mascaro trying to understand how his discourse thematizes the Brazilian social inequality. The concepts of discourse analysis (Maingueneau, 2008a; 2008b) and studies of Penafria (1999) and Nichols (2001) are mobilized. The distinction between both the spatial/social positions of the I - dweller of coverage apartment- and the Other, and the construction of subjects linked to values of superiority, individualism and privilege allows the documentary to report social alienation.

Keywords: cities; urbanization; discourse analysis; social inequality; documentary.

* Natália Martins Flores: Universidade Federal de Santa Maria, Faculdade de Comunicação Social, Departamento de Ciências da Comunicação. CEP 97070-360, Santa Maria, Rio Grande do Sul, Brasil. E-mail: nataliflores@ gmail.com

Isaltina Maria de Azevedo Mello Gomes: Universidade Federal de Pernambuco, Faculdade de Comunicação Social, Departamento de Ciências da Comunicação. CEP 50670-901, Recife, Pernambuco, Brasil. E-mail: isaltina@gmail.com

Submissão do artigo: 02 de novembro de 2016. Notificação de aceitação: 13 de fevereiro de 2017

Doc On-line, n. 21, março de 2017, www.doc.ubi.pt, pp. 114-132. 
Os espaços do Eu e do Outro: a tematização da desigualdade social no documentário brasileiro Um lugar ao sol

Résumé: On se propose de mener ici une enquête sur la construction discursive de $U m$ lugar ao Sol (2009), de Gabriel Mascaro en essayant de comprendre comment son discours thématise l'inégalité sociale brésilienne, en s'appuyant essentiellement sur les concepts issus de l'analyse du discours (Maingueneau, 2008a; 2008b) et des études de Penafria (1999) et Nichols (2001). La distinction des positions spatiales/sociales entre le Je - les résidents des habitations situées en hauteur d'un immeuble et considérés comme privilégiés - et l'autre, et la construction de sujets attachés à des valeurs de supériorité, dl'individualisme et de privilège permet au documentaire de dénoncer l'aliénation sociale.

Mots-clés: villes; urbanisation; analyse du discours; inégalité sociale; documentaire.

\section{Palavras introdutórias}

Um dos gêneros discursivos com melhor capacidade de problematizar as desigualdades sociais contemporâneas é, sem dúvida, o filme documentário. O seu papel de apresentar significados que compõem a realidade social provoca, por si só, a reflexão e o debate (Penafria, 1999). Esse aspecto ganha importância significativa na sociedade brasileira, cuja identidade é marcada por relações sociais desiguais entre classes sociais, raças e gêneros. Documentários tornam-se dispositivos interessantes para tematizar o cotidiano social brasileiro, desnudando marcas culturais de violência e de distinção social que foram, de alguma forma, naturalizadas por nós.

Da produção brasileira de documentário, interessa-nos os filmes que focalizam a problemática das urbanidades e dos modos de habitação nos grandes centros urbanos brasileiros. Na cidade do Recife, no Brasil, particularmente, existe uma produção cultural pulsante que se propõe a tematizar a questão urbana. Temos como exemplos recentes os documentários Eiffel (2008), Menino-Aranha (2009), Praça Walt Disney (2011), Recife, cidade roubada (2014). Esses documentários retratam, cada um à sua maneira, o crescimento arquitetônico vertical desordenado da cidade do Recife, problematizando suas consequências sociais e urbanas. Em alguns casos, como no documentário Domésticas (2013), temos as desigualdades sociais tratadas de maneira mais explícita.

Neste artigo, analisamos o documentário Um lugar ao sol (2009), que segue a mesma linha temática de discussão do espaço público e das desigualdades sociais. ${ }^{1}$ Produzido pelo recifense Gabriel Mascaro, o longa-metragem diferencia-se de outros do gênero por ter como figura principal a elite brasileira, representada pelos depoimentos de oito moradores de coberturas das ci-

1. O documentário está disponível em: www.youtube.com/watch?v=pOH5SWK6Mcc. 
dades de São Paulo, Rio de Janeiro e Recife. A partir de um aporte teórico metodológico da Análise do Discurso, nos respaldando principalmente nos conceitos trabalhados por Maingueneau (2008a; 2008b), analisamos a construção discursiva do documentário focando no modo como ele tematiza a desigualdade social no contexto das cidades brasileiras. Interessa-nos também investigar os elementos que compõem o ethos discursivo das personagens do documentário, além dos modos de subjetivação implicados nesses discursos.

O documentário desvela o modo como esses indivíduos da classe alta falam de si e refletem sobre sua posição social frente a outras camadas sociais brasileiras. Interessa-nos analisar as formas como o documentarista trabalha esses depoimentos no fio do discurso do documentário e na composição do seu argumento. No seu conjunto, esses elementos compõem um olhar específico sobre o social, respaldado na emergência de determinados sentidos em detrimento de outros.

\section{O discurso, o sujeito e as narrativas da cidade}

O estudo da cidade e do espaço urbano transformou-se, há algum tempo, em interesse de pesquisa de analistas do discurso brasileiros. Projetos de pesquisa conduzidos pelo Laboratório de Estudos Urbanos (Labeurb), da Unicamp, mostram-nos modos de pensar a cidade a partir do viés da linguagem, relacionando as relações sociais no espaço urbano aos conceitos de discurso, sujeito e história. Segundo Eni Orlandi (2003), a perspectiva discursiva procura ressignificar os sentidos do social, do público e da cidade - muitos deles naturalizados pelo discurso do urbanismo - e refletir sobre o espaço urbano além das medidas geométricas de espaço. A cidade seria pensada, então, como um espaço simbólico, de convivência entre sujeitos e sentidos (Orlandi, 2003; 2004).

A abordagem discursiva concebe a produção do espaço urbano a partir de gestos históricos e sociais que significam, definindo sentidos sobre o que se entende por cidade e social (Orlandi, 2003; 2004). São materialidades como o rap, a poesia urbana, os grafites e as pichações, os painéis, os outdoors e os elementos da arquitetura da cidade que constroem as formas que o urbano pode tomar. No seu conjunto, esses elementos formam o que Orlandi (2004) nomeia de narratividade urbana que se materializa de maneira dispersa em diversos pontos cujas relações produzem sentidos.

A produção de sentidos no espaço urbano é marcada pela administração de pessoas que circulam nesse espaço - e que se constituem como sujeitos urbanos - e pelo controle do poder público. Essa última instância é responsável por selecionar os sentidos considerados legítimos na esfera burocrática 
Os espaços do Eu e do Outro: a tematização da desigualdade social no documentário brasileiro Um lugar ao sol

da cidade, fixando-os como "naturais" e de senso comum (Orlandi, 2004). Os analistas do discurso estão preocupados, justamente, em compreender como funciona essa engrenagem de seleção de sentidos, pois ela acaba por promover uma produção de sentidos uniformes sobre a cidade ao custo do silenciamento de outros sentidos possíveis.

A dinâmica de consolidação de sentidos sobre o espaço urbano encobre disputas sociais e discursivas que ocorrem nesse cenário. Há uma tentativa de estabilização de determinada rede de sentidos pelo político, processo que nos mostra que o discurso acaba por se constituir no próprio objeto de disputa entre sujeitos na construção do social. Esse argumento é característico das reflexões sobre o discurso. Concorda-se, assim, que

O discurso contribui para a constituição de todas as dimensões da estrutura social que, direta ou indiretamente, o moldam e o restringem: suas próprias normas e convenções, como também relações, identidades e instituições que lhe são subjacentes. O discurso é uma prática, não apenas uma representação do mundo, mas de significação do mundo, constituindo e construindo o mundo em significado. (Fairclough, 2001: 91).

Ora, se adotarmos as reflexões sobre a natureza do discurso para pensar a cidade, percebemos que as estruturas do urbano simbolizam e reproduzem as concepções e formas de habitar a cidade que nós consideramos legítimas. Intricadas a essas estruturas simbólicas, se produzem também subjetividades do urbano. Partindo de Foucault (1982), compreendemos que os discursos urbanos envolvem processos de subjetivação que conformam os indivíduos a determinadas verdades, discursos e sentidos de urbanização. Desse modo, pensar a cidade e o modo como os sentidos transitam nela envolve também questionarse sobre as próprias relações estabelecidas entre os sujeitos e a cidade. Esse argumento encontra respaldo nas reflexões do geógrafo David Harvey (2006):

Ao produzirmos coletivamente nossas cidades, produzimos coletivamente a nós mesmos. Projetos referentes ao que desejamos que sejam nossas cidades são em consequência projetos referentes a possibilidades humanas, a quem queremos ou, o que talvez seja mais pertinente, a quem não queremos vir a ser. Cada um de nós, sem exceção, tem algo a pensar, a dizer e a fazer no tocante a isso. A maneira como nossa imaginação individual e coletiva funciona é, portanto, crucial para definir o trabalho da urbanização. (Harvey, 2006: 210-211).

Estudos como os de Teresa Caldeira (2000) ajudam-nos a traçar um perfil dos modos de habitação valorizados nas cidades contemporâneas. A antropóloga concebe o conceito de enclave fortificado para nomear espaços privados voltados à coletividade que se multiplicam nos grandes centros urbanos a partir da década de 1990. Tidos como uma reação de defesa da classe média alta à violência crescente dos centros, os enclaves são espaços residenciais autônomos 
fisicamente demarcados e policiados por aparelhos e pessoas. Eles se tornam representantes de uma nova ordem urbana que enfatiza o valor do privado em detrimento de uma vida voltada aos espaços abertos da cidade.

Segundo nos mostra Orlandi (2004), as relações de sociabilidade foram ressignificadas na cidade moderna. Nessa cidade, o discurso da violência parece intrínseco à vida urbana, tornando "necessário" o isolamento no que a autora denomina bolsões: muros que separam e usam o discurso da hostilidade, da negação do Outro. O mecanismo social que liga sujeitos no mesmo espaço público desfaz-se em favor de um espaço privatizado, separado por barreiras, em que a convivência com indivíduos de outras classes e origens sociais se torna um risco. O que se produz, então, é uma violência simbólica social que separa indivíduos e diminui o espaço de sociabilidade entre eles (Orlandi, 2004). A cidade deixa de ser espaço público a ser compartilhado para virar uma série de bolsões que reproduzem intolerância e violência, além de reiterar a exclusão e o poder econômico.

Diante desse cenário, Orlandi (2004) afirma ser necessário pensar nos sentidos que estão sendo produzidos e reproduzidos no espaço social e o modo como eles têm moldado as relações entre sujeitos e cidade. Segundo ela, o papel dos pesquisadores que estudam a cidade seria o de apontar quais as ideologias e conceitos sobre o social e a cidade que se sedimentam na materialidade do espaço urbano. Esses elementos remetem ao tipo de sujeito urbano que estamos criando e a reflexões sobre quem nós somos e o que a cidade representa para nós.

\section{O documentário e sua cena de enunciação}

Os discursos e os sentidos sobre urbanização inscrevem-se em materialidades discursivas que circulam no ambiente social. Neste artigo, olhamos o documentário como uma dessas materialidades, a partir do conceito de cena de enunciação, de Maingueneau (2005; 2008a; 2008b). A cena de enunciação constitui-se a partir do entrelaçamento entre a cena global, a cena genérica e a cenografia. A cena global remete aos tipos de discursos presentes na materialidade, que definem a sua função social. Ela se relaciona aos setores da sociedade em que circulam os enunciados (discurso político, discurso literário, discurso publicitário) e permite aos sujeitos reconhecerem os campos discursivos a que pertencem os discursos. No documentário, a cena global mobiliza tipos de discurso distintos a depender do assunto e argumento de sua narrativa. Nos documentários sobre a cidade, essa cena se constitui, por exemplo, dos discursos político, de urbanização, entre outros, que se enredam na produção de sentidos. 
Os espaços do Eu e do Outro: a tematização da desigualdade social no documentário brasileiro Um lugar ao sol

A cena genérica apresenta-se como um nível mais detalhado da cena global e permitiria reconhecer os papeis de interlocutores de maneira mais específica (Maingueneau, 2005). Por essa razão, elegemos a cena genérica como elemento central para pensar o documentário. Ela remete aos gêneros dos discursos presentes na cena de enunciação, elementos que moldam as finalidades de comunicação e os papeis dos enunciadores. A partir dessa perspectiva, o documentário é um gênero audiovisual que define contratos de comunicação específicos entre os seus produtores e público. Sua estrutura genérica mobiliza tipos de discurso (da cena global) e cenografias específicas com a finalidade de narrativizar uma realidade.

Os estudos sobre documentário de Manuela Penafria (1999) e Bill Nichols (2001) ajudam-nos a delinear as características específicas desse gênero do discurso. Segundo eles, o documentário define-se por ser uma expressão do ponto de vista do documentarista sobre uma dada realidade filmada. Além de lhe dar um caráter autoral - em que identidades de documentário e documentarista fundem-se, inevitavelmente - essa colocação permite observar o filme documentário como uma narrativa baseada em um argumento que visa persuadir ou convencer o público sobre sua perspectiva (Nichols, 2001).

Apesar de basear-se em imagens da realidade, Penafria (1999) mostra-nos que o documentário se constitui como um recorte de fragmentos da realidade e não seu espelho. Assim,

[...] ao combinarem-se e interligarem-se as imagens obtidas in loco está-se a construir e a dar significado à realidade, está-se o mais das vezes não a impor significados mas a mostrar que o mundo é feito de muitos significados. Isto conduz-nos àquilo que se pretende que um documentário seja, que se exclua o voyeurismo ou mero sensacionalismo a favor do questionamento e da discussão através da construção de argumentos (em especial, e no meu entender, de modo visual - fazendo uso das imagens). (Penafria, 1999: 1).

Ora, se aproximarmos essas descrições do documentário à bibliografia sobre cidade e sentidos, percebemos que esse gênero tem potencial como forma de questionamento das estruturas da ordem urbana. De fato, muitos dos movimentos urbanos utilizam-se do dispositivo documentário como modo de se opor ao discurso burocrático e propor outras releituras sobre a cidade. Essas formas de discurso rompem com a ordem urbana estabelecida e alinham narratividades urbanas próprias que interessam aos analistas do discurso. Neste artigo, esse movimento é representado na forma do documentário Um lugar ao sol, cuja análise delineamos a seguir. 


\section{O lugar do eu e do outro: lógicas de distinção social}

O documentário Um lugar ao sol, como comentado anteriormente, se propõe a mostrar a realidade dos moradores de coberturas das cidades brasileiras. Para analisar as estratégias utilizadas na conformação do seu discurso, operacionalizamos o conceito de cenografia, de Maingueneau (2008a; 2013). A cenografia remete ao modo de encenação do discurso, a uma mis-en-scène da situação de comunicação, que é construído e validado progressivamente pela enunciação. Ela é:

[...] assim, esse elemento de onde vem o discurso e que engendra o discurso; ela legitima um enunciado que, por sua vez, deve legitimá-la, deve estabelecer que essa cenografia de onde a fala se origina é a cenografia apropriada para enunciar como convém em dadas circunstâncias. (Maingueneau, 2013: 78). (Tradução nossa).

A cenografia constitui-se em elementos linguístico-discursivos que o enunciador escolhe para colocar em cena sua enunciação. Ela configura um mundo ao definir os status para os interlocutores e, ao mesmo tempo, instaura um lugar e um tempo no qual se desenvolve a enunciação. Ela constitui o nível mais específico dos discursos e mantem relação com os outros níveis da cena global (esferas e tipos de discurso) e da cena genérica.

O fato dos enunciados de Um lugar ao sol pertencerem ao gênero documentário já permite observarmos alguns elementos de sua cenografia. Estamos nos referindo, basicamente, ao que chamamos de efeitos de sentido de realidade e de persuasão, que marcam os discursos desse gênero específico. Os efeitos de realidade aparecem no documentário no seu apelo a estratégias de verossimilhança com a realidade social filmada. Mesmo que admitamos que o documentário seja uma montagem de fragmentos do real, a sua tradição vem marcada por essa exigência de impressão de autenticidade (Nichols, 2001). Imbricados a esses estão os efeitos de persuasão, que se referem à necessidade da narrativa do documentário de convencer o público sobre seu argumento.

$\mathrm{O}$ falar de si aparece como argumento condutor deste documentário. Ele é desempenhado pelos depoimentos das personagens que ocorrem ao longo da sua narrativa sobre suas experiências de se morar em uma cobertura. A construção do ponto de vista desses sujeitos, que produz efeitos de sentido de realidade, é reiterada por outros elementos da cenografia desse discurso, como o cenário de filmagem e o enquadramento da câmera. $O$ cenário é a própria sala de estar das coberturas, ambiente privado dos entrevistados. $\mathrm{O}$ enquadramento espacial, do entrevistado sentado no seu sofá, de frente para a câmera, constrói um efeito de sentido de unidade entre criatura e habitat, na construção do discurso sobre si. 
Os espaços do Eu e do Outro: a tematização da desigualdade social no documentário brasileiro Um lugar ao sol

A questão da espacialidade ganha destaque na construção da cenografia do discurso do documentário. Ela aparece tematizada na fala dos entrevistados, no enquadramento da câmera e nas imagens/externas colocadas entre uma entrevista e outra. No seu conjunto, esses elementos constroem duas espacialidades: 1) o espaço de si - do sujeito que habita coberturas e 2) o espaço do outro, dos não privilegiados que não moram em coberturas. Enquanto o espaço de si é personificado na figura do personagem/habitat, do espaço do apartamento, o espaço do outro é representado pelo espaço das ruas e das favelas, posicionadas entre uma entrevista e outra. Esses últimos ambientes são reiterados como espaços exteriores que circundam o ambiente interno do apartamento, mas não pertencem à sua rede de significados.

A demarcação dos espaços sociais de si e do outro no discurso do documentário encontra-se marcada pela lógica de distinção entre espaço privado e público presente na cultura das cidades brasileiras contemporâneas. O antigo espaço público, representado pelo centro das cidades, em que reinam elementos como a pobreza, a sujeira e a heterogeneidade social, apresenta-se como espaço a ser minimizado diante da lógica do espaço privado do apartamento. As práticas sociais de valorização da propriedade privada dos condomínios reiteram essa lógica de ruptura entre esses espaços (Caldeira, 2000).

As distinções entre espaço privado e público aparecem em vários trechos do documentário, na fala dos entrevistados e nas imagens do lugar da rua e o lugar da cobertura (figura 1). Enquanto o primeiro é representado como um lugar de caos e heterogeneidade urbana - pelo trânsito de carros (como na imagem) e movimento de transeuntes - o espaço da cobertura é representado como um lugar silencioso, tranquilo, habitado por poucas pessoas com o mesmo estilo de vida. Esse choque entre efeitos de sentido de caos e tranquilidade configura a cenografia do documentário, sendo representado também pela oposição entre elementos estéticos como imagens de guindastes e canteiros de obras (que tematizam o ambiente urbano) e as salas amplas e silenciosas das coberturas. 


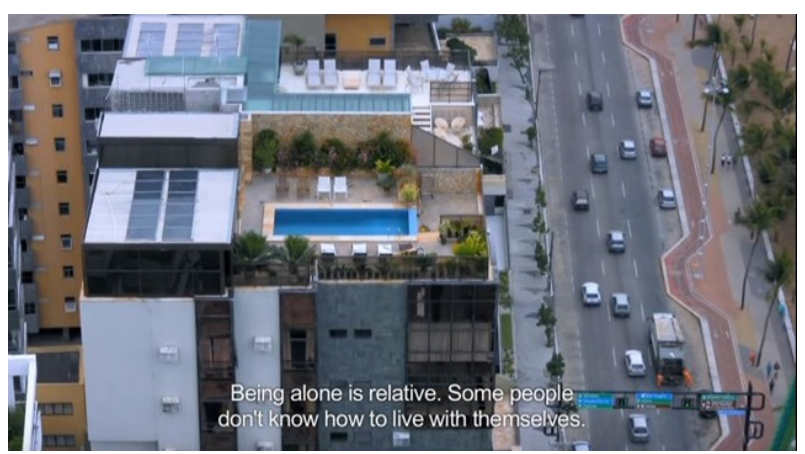

Figura 1. Entre o silêncio da cobertura e o caos da cidade Fonte: www.youtube.com/watch?v=pOH5SWK6Mcc

As escolhas discursivas do enunciador em Um Lugar ao sol conformam um tom de crítica à estrutura urbana vigente, de crescimento desenfreado das cidades e valorização do espaço privado em detrimento do espaço público. Esse tom constrói-se pela justaposição de imagens de construção de prédios com elementos como plantas arquitetônicas e placas de apartamentos à venda em condomínios - a uma trilha sonora pesada, que dão um ar de tensão ao documentário. A crítica desnuda-se quando observamos o contexto sócio cultural no qual o audiovisual emerge. Conhecida por seus arranha-céus, a cidade do Recife é cenário, já há alguns anos, de lutas simbólicas entre movimentos sociais e os consórcios imobiliários pela cidade. $\mathrm{O}$ olhar do documentarista deriva da matriz discursiva de movimentos sociais como o Ocupe Estelita, que advoga pelo direito à cidade e outras formas de habitar o espaço urbano, confrontando o discurso hegemônico recifense sobre urbanização.

As justaposições entre o espaço privado do condomínio e o espaço público das ruas materializam as relações desiguais existentes entre as classes sociais brasileiras. A habitação em condomínios torna-se um fator de distinção social para as classes média e alta em relação a outras classes que supostamente não teriam acesso a esse modo de vida. Essa distinção aparece até na escolha do nome dos prédios das cidades brasileiras, foco mostrado pela narrativa do documentário. Nomes como Versailles, Cannes, Rembrandt, Akrópolis, Renoir e Conde de Toulon relacionam simbolicamente o estilo de vida dos moradores desses prédios à cultura europeia e, especificamente, à nobreza francesa. Reitera-se um discurso que coloca essa cultura numa posição de superioridade em relação à cultura brasileira mestiça e, portanto, impura.

O discurso de distinção social torna-se ainda mais explícito quando se trata de apartamentos cobertura, já que o seu número é reduzido em relação a ou- 
Os espaços do Eu e do Outro: a tematização da desigualdade social no documentário brasileiro Um lugar ao sol

tros tipos de habitação urbana. Segundo as falas dos moradores entrevistados, habitar em uma cobertura significa ter acesso a valores diferenciados de conforto e privacidade, encarnados na expansão do espaço físico do apartamento. Além disso, a posição espacial em que a cobertura se encontra - de estar acima de outros apartamentos - confere aos seus habitantes uma "sensação de domínio", segundo as palavras de uma das moradoras. Na fala de outros moradores, a cobertura é descrita como uma ilha: isolada do restante da vida social, como “outra dimensão", "outro plano", "acima de tudo" e de todos.

Algumas falas dos moradores das coberturas trazem marcas explícitas de distinção social em relação ao outro, materializado na figura do empregado da classe subalterna, reiterando um discurso classista. Vejamos na fala de uma das moradoras, no exemplo 1:

Exemplo 1: Outra coisa também que eu adoro é que a área de serviço - não é que eu tenha nada contra o pessoal que trabalha comigo, que são pessoas que até fazem 25 anos, uma tem 25 anos, outra tem 15, o motorista tem mais 15. Realmente são pessoas, assim... mas a gente já não ouve, a gente fica com mais privacidade pra ficar sozinhos (...) Mesmo se o apartamento fosse enorme, você sempre ouve, vamos dizer assim, batida de panela, que isso me deixa realmente agoniada. Aquelas batidinhas, aquela conversa... a conversa não é tanto, realmente é a panela, propriamente. Perde a privacidade... enfim, são algumas coisas que você não deixa, do seu dia a dia, incomodar um pouco.

No trecho, observamos a existência de um discurso classista que impõe separações espaciais nítidas entre a elite e a classe subalterna de empregados como necessárias para garantir o conforto e privacidade dos primeiros. Articula-se, aqui também, uma divisão entre espaços privado/público. A cozinha é descrita como o espaço desordenado dos funcionários da casa - das batidas de panelas e conversas - enquanto a sala aparece como um lugar silencioso e privado da moradora. Rememoram-se, em certo sentido, as figuras da casa grande e da senzala da época do colonialismo, que definiam, de modo estrito e controlado, a quais ambientes as classes sociais pertenciam.

Esse discurso ganha um tom cordial, representado pela fala da moradora de que "não tem nada contra" seus empregados, apesar de não se misturar e não gostar do barulho das panelas. Essa retórica, muito presente nos discursos brasileiros sobre preconceito racial e de classe, é utilizada pelo enunciador como forma de evitar julgamentos do seu interlocutor. Trata-se de preservar as faces, como diria Goffman (1980). Os funcionários e empregados são valorizados por essa moradora contanto que eles ocupem o espaço deles e, assim, mantenham distantes barulhos e outros elementos associados à sua classe social. 
Para além da figura do empregado, o outro é representado nas falas dos moradores como um ente que transita pela vizinhança do prédio, cujos passos são observados a distância pelos moradores das coberturas. Cria-se, nos discursos dos moradores, uma separação estratégica entre esses sujeitos e universos, que reitera as lógicas de distinções de classe da sociedade brasileira. Isso é marcado, por exemplo, na fala de um morador do Recife, quando diz que prefere observar o movimento de pessoas indo à praia de Boa Viagem no silêncio $\mathrm{e}$ isolamento de sua cobertura, a misturar-se à multidão e ao desconforto de uma praia lotada. Mais uma vez, reiteram-se o lugar do eu, pertencente ao mundo da cobertura, e do outro, relegado a um espaço conturbado e heterogêneo.

Colocado a distância, o outro nunca chega a ser concretamente materializado nas imagens do audiovisual e, muito menos, nos depoimentos dos moradores. Essas falas revelam mais sobre o estilo de vida isolado e solitário da cobertura do que sobre a presença do outro nas cenas do cotidiano. Essa abordagem transforma esse sujeito em um espectro cuja presença e proximidade simbólica é sempre um risco. Ora, a cobertura serve justamente como ponto de vigilância e de controle deste outro, possibilitando ao morador observá-lo a partir do alto sem, no entanto, fazer-se ver. Esse jogo de vigilância pode ser comparado ao modelo de panóptico das prisões analisadas por Foucault (1977), no livro Vigiar e Punir. Semelhante à forma arquitetural do sistema prisional descrita no livro, a cobertura possui certo poder de submeter a rua e seus indivíduos a uma vigilância contínua, sem fornecer a eles a possibilidade de ver quem os está observando.

Em um trecho do documentário, o documentarista brinca com essas práticas de vigiar o outro ao mostrar a imagem de uma das moradoras com uma câmera filmadora na mão, filmando a vizinhança do seu apartamento (figura 2). Na sequência, o enquadramento da imagem do audiovisual é conformado pelas próprias imagens coletadas pela câmera da observadora, dos morros e favelas nas proximidades. Essa estratégia discursiva de inserção dessas imagens marca discursivamente o vigiar e a construção do outro por meio das lentes do eu. 


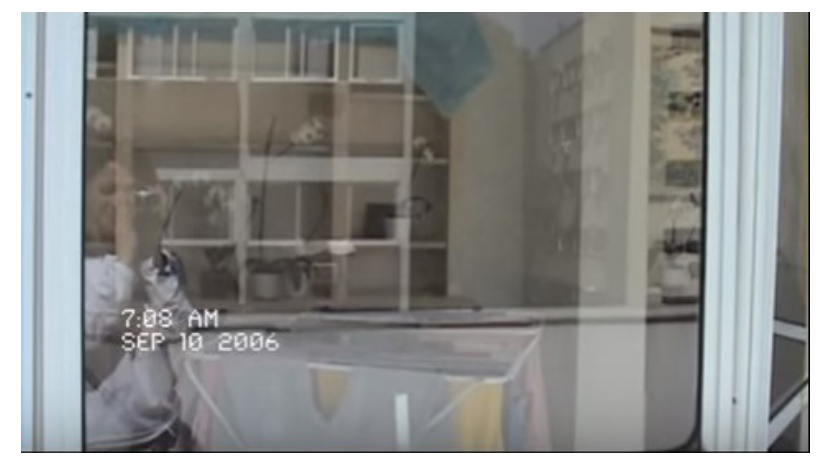

Figura 2. O outro através das lentes do eu www.youtube.com/watch?v=pOH5SWK6Mcc

O olhar do eu através das lentes do outro - constituído a partir desse enquadramento - conforma-se também pela narração da moradora sobre o que ela está observando. Esses elementos ajudam a constituir uma representação do outro no discurso do eu, que não passa de um simulacro, já que o contato que a moradora tem com esses sujeitos de quem fala é mediado por meio de dispositivos (a cobertura e a câmera) capazes de manter a distância entre esses sujeitos. No exemplo 2, trazemos um trecho da narração da moradora para mostrar a representação deste outro:

Exemplo 2: Não sei se tu vai poder ver daqui [o morro da] Dona Marta. [pausa] Você tem uma comunidade que adentra o morro, que desmata a montanha, que não preserva, que faz uma coisa fechada, nessa comunidade que cria regras próprias, e que tão perto, tão longe, fazem um bangue bangue. [pausa] A gente assiste essa guerra, sem participar desta guerra, muitas vezes sentindo a consequência de estar tão perto dessa guerra.

A moradora utiliza a narração para conduzir o olhar do documentarista, que a acompanha, sobre o que deve ser observado na paisagem que ela está filmando, cujas imagens são mostradas concomitantemente. Em seguida, a moradora descreve esse outro - representado pelos habitantes do morro da Dona Marta - como um sujeito que construiu sua comunidade de modo depredatório e invasivo (o que é marcado pelo uso de marcas textuais "adentra o morro", "desmata a montanha" e "não preserva"). O uso do tempo verbal do presente do indicativo remete ao fato de essas ações serem contínuas, ou seja, de ainda estarem se desenrolando.

O outro também aparece representado, nesse trecho, como uma estrutura social fechada e isolada, por meio do uso das expressões "comunidade" e "uma coisa fechada" para referenciar esses sujeitos e "cria regras próprias", como modo de descrever como suas práticas sociais são sedimentadas. Essas ex- 
pressões criam um sentido de distanciamento do eu e do outro, ao mostrar que o universo desse outro funciona por meio de códigos e lógicas próprias, diferentes dos códigos e leis da sociedade. Esse distanciamento também se constrói por meio do uso da expressão "tão longe, tão perto". O tão longe se refere a esse outro universo simbólico desconhecido da moradora, dos códigos fechados e da violência do tráfico. O tão perto traz à tona a proximidade espacial existente entre esse universo e a cobertura.

Se lançarmos um olhar interpretativo sobre as escolhas linguístico-discursivas usadas pela moradora para representar o outro, percebemos que os elementos usados para caracterizar a ocupação do morro da Dona Marta e seus modos de convivência podem ser, facilmente, transpostos para a caracterização dos condomínios fechados da elite brasileira. O modo de apropriação do espaço urbano operado por esses últimos faz-se por meio de uma construção desenfreada e especulação imobiliária que, por vezes, também não respeita as legislações e espaços ambientais. Os enclaves fortificados também criam suas regras de convivência própria àquele espaço interno, baseado na homogeneidade social de seus habitantes (Caldeira, 2000). A única diferença é que o tipo de violência que a moradora descreve é deixado do lado de fora de seus portões.

\section{O ethos e a privatização das experiências}

Desvendar as estratégias de funcionamento do discurso do documentário Um lugar ao sol significa também nos determos no modo como suas personagens são construídas a partir do conceito de ethos discursivo. Maingueneau (2008a; 2008b) refere-se ao ethos como uma maneira de ser e de dizer relacionada a uma identidade da posição discursiva de um sujeito. Responsável por unificar uma corporalidade para o discurso, por meio da representação de traços psicológicos e físicos para o enunciador, o ethos mobilizaria o coenunciador a aderir a um discurso específico e seu universo de sentido.

Existem dois tipos de ethos que constituem o discurso do documentário analisado: 1) o ethos do enunciador, encarnado na figura do documentarista, cuja visão de mundo estrutura as escolhas discursivas e 2) os ethos das personagens que, no seu conjunto, constroem uma representação da maneira de ser da elite brasileira. Vemos que essas duas construções discursivas atuam mútua e conjuntamente para convencer e persuadir o público da validade e veracidade desse discurso. Aqui, interessa-nos delinear os elementos que compõem o ethos das personagens do documentário, já que neles transitam sentidos que nos levam a refletir sobre a desigualdade social. 
Os espaços do Eu e do Outro: a tematização da desigualdade social no documentário brasileiro Um lugar ao sol

Os caracteres do ethos das personagens moldam um sujeito superior, individualista e privilegiado. Esses elementos aparecem entrelaçados e mantêm relação com os sentidos dados à cobertura, fundindo esses sujeitos ao seu habitat. Com Maingueneau (2008a), observamos que esses caracteres se constituem a partir de duas formas sobrepostas na formação do ethos: o ethos dito e o ethos mostrado. O ethos dito remete a enunciados em que o enunciador evoca sua própria enunciação, demarcando-se explícita ou implicitamente no texto. Ele seria marcado no falar de si das entrevistas das personagens. De outro modo, o ethos mostrado traria elementos que configuram a cenografia do enunciado sem estarem explicitamente ditos no enunciado. Seriam os elementos audiovisuais de edição/montagem do documentário que também produzem sentidos.

A característica de superioridade faz referência à sensação de domínio e de se estar acima de todos trazidos pela localização espacial e pela distinção social da cobertura. Ela vincula-se a um olhar onisciente sobre a realidade social e marca-se, no discurso do documentário, por meio da fala dos sujeitos entrevistados e por tomadas de vídeo do próprio ambiente. As tomadas da vista do mar filmadas a partir do ambiente interno de um elevador que sobe até a cobertura e as tomadas de prédios feitas a partir da rua exemplificam os efeitos de sentido de superioridade fornecidos pela imagem.

A superioridade configura uma identidade de classe das pessoas que habitam coberturas, cujos gostos e percepções de espaço são diferenciados. Ela proporciona um descolamento do sujeito dos fatos cotidianos da vida social. É como se o fato de morar em uma cobertura permitisse a esse sujeito observar e presenciar eventos sociais a distância, sem necessariamente se envolver neles. Esse aspecto é salientado, por exemplo, por uma moradora de cobertura do Rio de Janeiro, quando comenta que ela escuta assaltos e outros eventos de violência que ocorrem lá embaixo, na rua. Para ela, é como se a cobertura afinasse os seus sentidos. A violência é presenciada de longe, vista e ouvida de cima, sem atingi-la diretamente.

A construção de uma identidade de classe de moradores de cobertura nos conduz à característica de individualismo, expressa no ethos das personagens. Esse valor é nutrido por classes altas, que tem o indivíduo e sua individualidade como núcleos autônomos. No documentário, esse caráter constrói a imagem de um sujeito solitário cujo passatempo é aproveitar o tempo sozinho no conforto de sua própria casa. Essa construção discursiva aparece por meio de escolhas de enquadramento da câmera e nas falas das personagens. Opta-se por enquadrar indivíduos sozinhos na sua sala de estar (figura 3) ou junto aos membros de sua família, que tem, no máximo, três pessoas. 


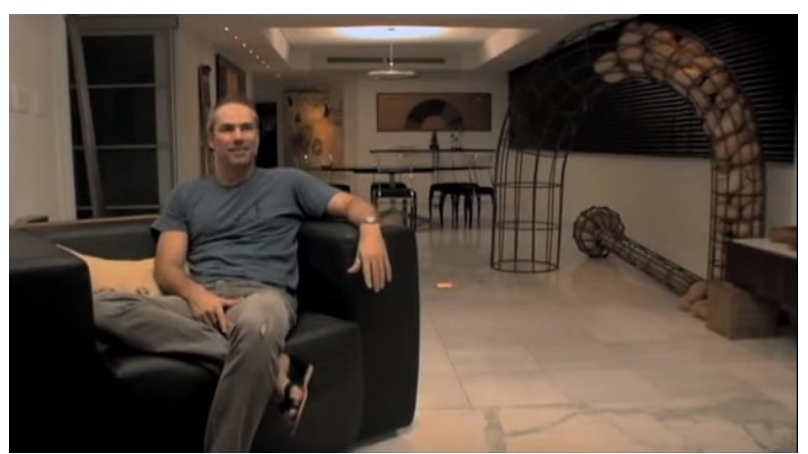

Figura 3. Enquadramento da câmera constrói ethos de sujeito individualista Fonte: www.youtube.com/watch?v=pOH5SWK6Mcc

Escolhemos como exemplo a figura 3 justamente devido ao fato de a fala desse personagem reforçar o ethos de sujeito individualista, convergindo com o enquadramento da imagem na produção de sentidos. Esse sujeito fala sobre o seu cotidiano, como as festas que tem promovido no espaço da cobertura ou o tempo que tem passado sozinho. Ele discorre sobre o fato de conviver bem com a solidão e traça um perfil de um indivíduo divorciado cuja principal preocupação atual é apenas com o seu conforto. O fato de não mencionar em nenhum momento a rotina com sua família mostra-nos que ele encarna os valores individualistas e o estereótipo de solteirão que quer aproveitar a vida. Talvez o fato de retratar esses sujeitos no seu isolamento seja uma estratégia do documentarista para mostrar como essa classe não se relaciona plenamente com o outro.

Por fim, a última característica identificada nos ethos das personagens é o de sujeito privilegiado. Esse privilégio é vinculado à posição social, que confere a esses sujeitos um acesso a produtos e serviços diferenciados - "os melhores hotéis, os melhores relógios, as melhores roupas, as mulheres bonitas, as boas comidas, os bons carros", nas palavras de um dos moradores de cobertura. O fato de habitar em uma cobertura concretizaria esse universo de privilégios distintos. Além desses, os privilégios também aparecem na fala desses sujeitos no seu acesso à natureza que circunda seu apartamento. Segundo eles, o olhar do alto proporciona uma vista diferenciada das paisagens naturais e do mar, já que as coberturas são à beira mar. Eles assumem, então, um discurso de contemplação da natureza acessível aos seus olhos.

É interessante notar a relação de proximidade que alguns dos moradores estabelecem entre eles, a natureza e Deus. Vejamos nos exemplos 3 e 4: 
Os espaços do Eu e do Outro: a tematização da desigualdade social no documentário

Exemplo 3: O Rio de Janeiro é um privilégio e eu sou mais privilegiada ainda porque eu sempre morei olhando por cima. Eu vejo as coisas como se eu tivesse até, sei lá, pertinho do céu mesmo.

\section{Exemplo 4:}

[Morador 1]: Realmente, humildade quebra qualquer preconceito, qualquer recalque que possa existir de alguém que tem um pouquinho a mais ou a menos que o outro, porque perante a Deus... E existe um Deus nesse mundo hein. Tá vendo, taí uma das vantagens de viver numa cobertura.

[Cineasta] Tá mais perto de Deus?

[Moradora 2]: É, porque nós podemos falar com Deus aqui mais facilmente né.

[Morador 1]: (risos)

Nos dois exemplos, percebe-se que as personagens evocam a posição espacial da cobertura como sinônimo de estar fisicamente mais próximo do céu (exemplo 3) e, consequentemente, de Deus (exemplo 4). Esse acesso permite a eles se diferenciarem, mais uma vez, dos não privilegiados que não habitam coberturas. Em algumas entrevistas, os moradores ainda associam Deus ao ente responsável por lhes oferecer a chance de contemplarem a natureza que os circunda, razão pela qual eles se consideram privilegiados e gratos.

\section{A naturalização da desigualdade social}

Elemento central da cenografia do documentário Um lugar ao sol, o falar de si somente existe devido à sua relação com o outro. Esse outro se encarna na figura do sujeito que não habita coberturas, cujo espaço é demarcado em oposição ao espaço de si. Vemos configurar-se, então, uma naturalização dos espaços desses dois sujeitos que, inevitavelmente, conduz a uma aceitação da desigualdade social existente entre eles. Vejamos um exemplo de como esse processo funciona:

Exemplo 5: A própria sociedade, quando você chega ali embaixo e diz para o zelador, "eu vou na cobertura", as pessoas já tem veem de uma forma diferente. É assim. No avião você tem a primeira classe, a executiva, depois você tem a senzala lá no fundo. Na sociedade, você tem mulheres com bolsa Louis Vuitton e você tem mulheres com saquinho plástico na mão, na sociedade, você tem pessoas que andam de fiat, carro velho, e você vê pessoas que andam de Mercedes e Jaguar. Como eu me sinto? Eu me sinto muito bem. Eu vim ao mundo pras coisas boas da vida, pros prazeres da vida.

No trecho, o morador coloca a sociedade na posição de legitimadora dos espaços sociais e da diferenciação entre eles, já que são as pessoas que "veem" os habitantes de coberturas "de forma diferente". A enunciação utiliza recursos que assumem a lógica da distinção social como um modo natural de funciona- 
mento da sociedade, de algo que "é assim" e que, por essa razão, não precisa ser mudado. A seguir, o sujeito enumera as diferenças de classe, por meio de pares de oposição de bens de consumo de ricos e de pobres ("bolsas Louis Vuitton"/ "saquinho plástico", "Fiat" e "carro velho"/ "Mercedes e Jaguar"). Essa diferenciação remete ao universo histórico discursivo brasileiro, marcada no discurso do morador pela oposição espacial "primeira classe/senzala". A naturalização desses espaços funciona como mecanismo de expiação da culpa do morador, que se descreve como um sujeito feito para os "prazeres da vida" e que se sente bem com isso.

Em algumas falas, vemos emergir um discurso meritocrático que acredita na relação direta entre trabalho e posição social. De acordo com essa matriz discursiva, a situação social dos indivíduos seria resultado de esforços pessoais, não dependendo dos contextos sociais em que eles estão inseridos. Um dos moradores entrevistados adota esse discurso ao comentar que a cobertura e seu estilo de vida foram conquistados pelo trabalho de seus pais e que não é meramente herança. Esse argumento reitera estereótipos e relações causais de que classes mais abastadas são trabalhadoras e, por isso, conseguem riqueza, enquanto as classes humildes são preguiçosas, a quem falta persistência para "ganhar na vida".

A naturalização da desigualdade social vem acompanhada de uma alienação dos moradores em relação a outras classes sociais. É como se o pertencimento deles à classe dos privilegiados implicasse uma inabilidade para se colocar no lugar do outro, das classes humildes. Em alguns casos, a alienação é encarnada por um discurso que beira o irônico. Isso ocorre, por exemplo, no discurso de uma das moradoras sobre violência no Rio de Janeiro, em que ela descreve o fogo cruzado presente nas favelas vizinhas como "balas coloridas tracejantes" que a distraem e divertem enquanto ela admira sua vista privilegiada. A realidade violenta por trás daqueles sinais ganha ares de beleza e contemplação no discurso da entrevistada, que escolhe ignorar seus aspectos problemáticos.

A alienação social cede espaço, apenas, em uma das entrevistas, em que a moradora fala sobre o trabalho de voluntariado desenvolvido por ela e outras socialites da sociedade recifense. Sua fala, no entanto, vincula-se ao discurso do senso comum sobre caridade, que a liga a uma necessidade de realização individual de servir ao próximo. Segundo ela, a vida de uma pessoa só teria sentido se ela fizesse o bem ao outro, aspecto que é contrastado por ela com a realidade de egoísmo do mundo atual. Ao conceber a caridade a uma iniciativa individual, esquece-se de problematizar as questões sociais a partir de 
Os espaços do Eu e do Outro: a tematização da desigualdade social no documentário brasileiro Um lugar ao sol

um prisma coletivo e social. Assim, não se abordam questões mais profundas sobre a desigualdade social e formas de transformar essa realidade.

\section{Considerações Finais}

Analisamos, neste artigo, o documentário Um lugar ao sol, apontando os modos como ele tematiza a desigualdade social e os processos de subjetivação e de construção do ethos discursivo de suas personagens. Observamos que a cenografia do documentário se produz por meio da espacialidade e de uma demarcação visual e discursiva dos espaços de si - do morador da cobertura - e dos espaços do outro. Essa divisão remete aos espaços sociais e históricos do privado, dos ideais de conforto e tranquilidade e do público, espaço da heterogeneidade e da desordem. Ao ressaltar essas diferenças, o documentário problematiza os processos de valorização do privado e de consequente escamoteação dos espaços públicos, presente na realidade brasileira atual.

Sobre o ethos das personagens, vemos surgir um sujeito com características de superior, individualista e privilegiado. O privilégio de habitar em uma cobertura é colocado como tema central nas falas dos moradores, assim como a presunção de que a ocupação deste espaço os transforma, de algum modo, em seres superiores. A visão de mundo das personagens torna-se problemática quando percebemos que ela aparece vinculada a um discurso classista e alienado de distinção social, que não consegue enxergar nem tematizar propriamente a desigualdade social brasileira. A naturalização da desigualdade social e a alienação dos moradores de cobertura em relação a outras classes sociais são bem marcadas e ficam explícitas em Um lugar ao sol.

A construção desse tipo de subjetividade consiste em uma estratégia discursiva do documentarista, com o objetivo de fazer refletir sobre a realidade social brasileira e a produção de desigualdades e distinções entre classes. O documentário firma-se, mais uma vez, como esse espaço de (re)formulação de discursos capaz de provocar uma tomada de consciência sobre questões sociais pouco visíveis aos nossos olhos no cotidiano.

Reconhecemos que neste artigo analisamos um corpus bastante restrito, mas acreditamos que, tomando-o como marco inicial, podemos avançar na análise do que é produzido sobre a temática da desigualdade social. Queremos dar continuidade a esse trabalho, reunindo outros documentários, tanto pernambucanos como nacionais, para, com um corpus mais expressivo, podermos categorizar, analisar e expressar uma determinada visão de mundo em relação à pobreza e à desigualdade. 


\section{Referências bibliográficas}

Caldeira, T. (2000). Cidade de muros: crime, segregação e cidadania. São Paulo: Edusp.

Fairclough, N. (2001). Discurso e mudança social. Brasília: Editora UnB.

Foucault, M. (1982). A hermenêutica do sujeito. São Paulo: Martins Fontes.

Foucault, M. (1977). Discipline and punish: the birth of the prison. Harmondsworth: Penguin.

Harvey, D. (2000). Espaços de esperança. São Paulo: Edições Loyola.

Goffman, E. (1980). A Elaboração da face - uma análise dos elementos rituais da interação social. In S. Figueira (org.), Psicanálise e ciências sociais. Rio de Janeiro: Francisco Alves.

Maingueneau, D. (2013), Genres de discours et web: existe-t-il des genres web?. In C. Barats (org.), Manuel d'analyse du web (pp.74-93). Paris: Armand Colin.

Maingueneau, D. (2008a). Cenas da enunciação. São Paulo: Parábola Editorial.

Maingueneau, D. (2008b). Ethos, cenografia e incorporação. In R. Amossy, Imagens de si no discurso: a construção do ethos (pp.68-92). São Paulo: Contexto.

Maingueneau, D. (2005). Análise de textos de comunicação. São Paulo: Cortez.

Nichols, B. (2001). Introduction to documentary. Indiana: Indiana University Press.

Orlandi, E. (2004). Cidade dos sentidos. Campinas, São Paulo: Pontes.

Orlandi, E. (2003). Polisêmico. In E. Orlandi (org.), Para uma enciclopédia da cidade (pp. 21-63). Campinas, São Paulo: Pontes, Labeurb/Unicamp.

Penafria, M. (1999). Perspectivas de desenvolvimento para o documentarismo. BOCC - Biblioteca Online de Ciências da Comunicação. Disponível em: www.bocc.ubi.pt/pag/penafria-perspectivas-documentarismo.pdf

\section{Filmografia}

Um lugar ao sol (2009), de Gabriel Mascaro. 